\title{
A hybrid control system for investigating a high level of decision in internet of things
}

\author{
Mohanad Ali Meteab Al-Obaidi ${ }^{1}$, Basim Jamil Ali ${ }^{2}$, Jamila H.Ssaud ${ }^{3}$, Tole Sutikno ${ }^{4}$ \\ ${ }_{1,2,3}$ Al-Mustansiriya University, College of Science, Department of Computer Science, Iraq \\ ${ }^{4}$ Department of Electrical Engineering, Universitas Ahmad Dahlan, Indonesia \\ ${ }^{4}$ Embedded System and Power Electronics Research Group (ESPERG), Indonesia
}

\begin{tabular}{l} 
Article Info \\
\hline Article history: \\
Received Nov 12, 2019 \\
Revised Apr 18, 2020 \\
Accepted May 21, 2020 \\
\hline Keywords: \\
Hybrid control system \\
Internet of things \\
Remote control \\
Street lighting systems \\
Traffic lights
\end{tabular}

\begin{abstract}
In the modern world, the search started for cheap and efficient operating system sources has begun can converted to civilian ends. Internet of things (IoT) is one of the most realistic applications for remote control and remote management using a wide network. In this paper, a control system is designed and built to manage and control traffic lights and street lighting systems, as well as turning on/off generators in a small virtual environment. This was implemented by designing and building a hybrid electronic circuit that combines the closed-circuit control system and the open circuit system. The closed circuit regulates the system according to the desired condition without operator interaction; while the open circuit operates on demand. This type of a hybrid control system demonstrated its high flexibility by controlling devices and its high efficiency compared to the closed circuit and the open circuit system independently. It also helps reduce the number of maintenance guys and energy consumption as well as the cost.
\end{abstract}

Copyright $(0) 2020$ Institute of Advanced Engineering and Science. All rights reserved.

\section{Corresponding Author:}

Mohanad Ali Meteab Al-Obaidi, Al-Mustansiriya University,

College of Science, Department of Computer Science, Baghdad, Iraq.

Email: neros2210@uomustansiriyah.edu.iq

\section{INTRODUCTION}

The Control systems are usually found in a number of practical applications manage people life, such as refineries robotics, manufacturing plants, chemical, traffic control [1,2], automated control system $[3,4]$, power systems, and space applications just to mention a few [5-7]. Resources can employees to successfully realize their tasks and targets, as a way to consolidate their well-being and their ability to do well [8-14]. The aim of any electronic control system is to organize, monitor and process commands, guidance and regulate the behavior of other devices or systems using many types of control systems [15, 16].

A control system is defined as a device or set of devices that manages and controls the behavior of another device or system. According to the viewpoint of some engineers, control systems can be classified into two types [6, 7]: open loop control system and closed loop (feedback) control system.

Open-loop system does not monitor or measure the condition of the output signal. In other words; the output signal is independent to the input signal. The circuit of the open loop system has not sensors to tell if their setpoint has been executed which makes the rectification of disturbances impossible. Open loop system works by simple input signals [16]. Its characteristics are not satisfactory in achieving the desired result of the system and observation so this system is too slow $[9,17]$.

Common examples for open loop (open source) of electronic circuits such as fan ventilation system, vacuum cleaner, home heating system (without sensor or feedback and control), system of traffic lights, switching and extinguishing street lamps along the way, sprinkler irrigation system. Feedback is not 
measured. The spray system can be activated on schedule, although there is no need to operate the system because the rain is already available [18-20]. Figure 1 shown the cycle system of open loop controller.



Figure 1. Cycle system of the open loop controller

Theory of closed-loop control is one of the most dynamic tools developed, was used to stabilize everything from satellite to oven temperature. Closed-loop control now includes a vast literature and countless applications [21, 22]. In closed-loop system the output signal is compared with the desired (input) signal through a feedback loop. According to this comparison, the feedback system makes a certain decision. Do not affected by any external or internal influences such as air conditioning and heating systems, automatic pump to raise water from the ground reservoir to the upper reservoir, autopilot and robots [23].

Closed circuit monitoring system in the computer processes the input signals, then sends signals to the devices under its control, e.g. light emitting diode (LED), relay, etc. to respond correspondingly. For example, in an automatic street lighting system, when the computer senses the light is dim, it will send instructions to the relay then the relay will turn on the street lamp which uses large current [24-27]. A computer control system, sensors are used to collect data and then enter the data to the computer for processing to make a decision. There are many types of sensors such as (mechanical sensors, pneumatic sensors, optical sensors, an electrical and light control system etc.) [28, 29]. Sensor can create electrical signals depending on external change. For example, the light sensitive resistor can be used as a light sensor, because of its resistance and the current it will change with the intensity of light in the environment. Input signals will be processed, and then sends output signals to the components under its control, for example, LED, relay, infra-red passive-red (PIR), and motion detector, etc. to carry out a procedure with, a closed loop system, Figure 2 illustrates this.

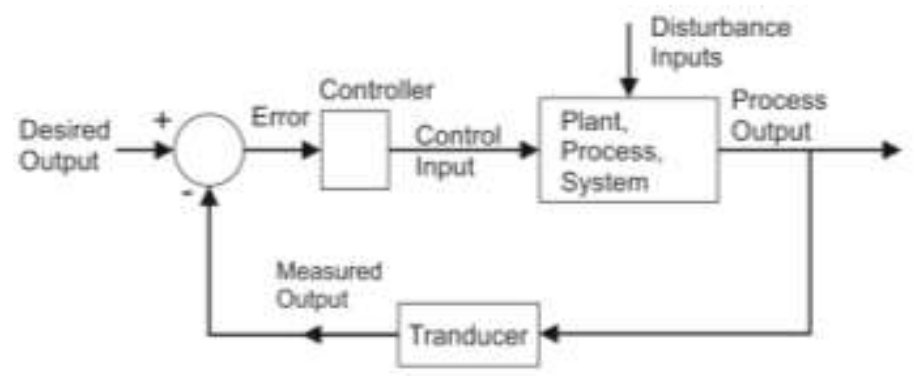

Figure 2. A basic closed loop control system architecture [12]

Durga [30] proposed a closed loop control system for controlling jam traffic. He used IR sensor, encoder and decoder ICs and 8051 micro controllers for measuring the traffic density. Banerjee [6] designed a control system for vehicle management based closed loop system using IC555 timer. Other researchers were designed automatic street light control system uses transistor as switch. They used LDR, PIC161F877A and PIC16F877A microcontrollers in control system [9, 31-35].

The main contribution of this paper establishes an integrated system to operate street lighting, control traffic lights, and operate generators for the virtual city. Two electrical circuits were built. The first is the use of relay systems that control the traffic light operating systems and of the generator. Therefore, two mixed systems were combined, which are the open system and the closed system of electrical circuits, and we called it the system Hybrid. All previous systems used the LDR circuit which was not externally controlled which means a significant consumption of electricity, no matter whether the street's illuminates are needed. 


\section{RESEARCH METHOD}

One of the most important problems in closed-loop circuits are that to provide a measure of control other parts of the circuit, so it must be more complex through in electronic construction, and the problem in open-loop circuit cannot control and measure the parts of an electronic circuit. An alternative system has been proposed to address their problems in the previous two systems, which is called hybrid control closed system as shown in Figure 3. In our proposed system some circumstances the control system requires frequent operator's intervention to force the system works as desired. In such a case the proposed system needs a high level of decisive action to work correctly and decision (or goal) through monitoring.

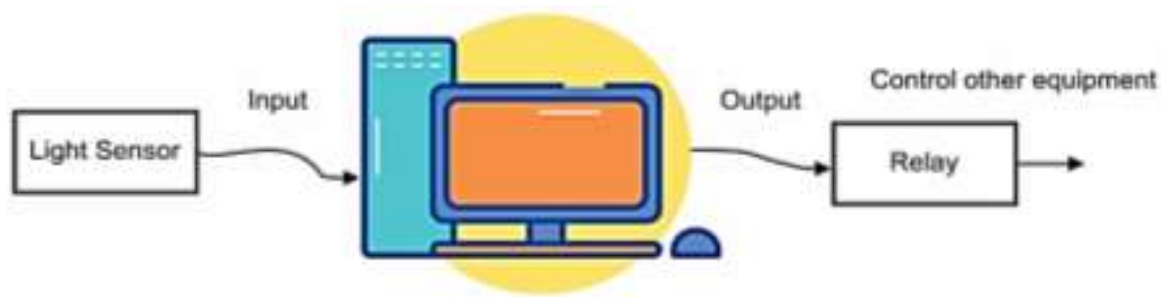

Figure 3. A hybrid control closed system

\subsection{General diagram of the proposed system}

Automata system for modern city consists of two parts; hardware such as: KIT circuit, diode, relay, resistors, transistor, LEDs, LDR, battery, parallel port (8 data pins and Ground pins) and software (which programmed by using V.B 6.0) for monitoring the system on the PC. Computer supplies power of $4.5 \mathrm{~V}$ via the parallel port. In addition, a transistor BC546 was adding to control the relay due to the minimum amount of ampere. Figure 4 illustrated the general diagram of our proposed system.

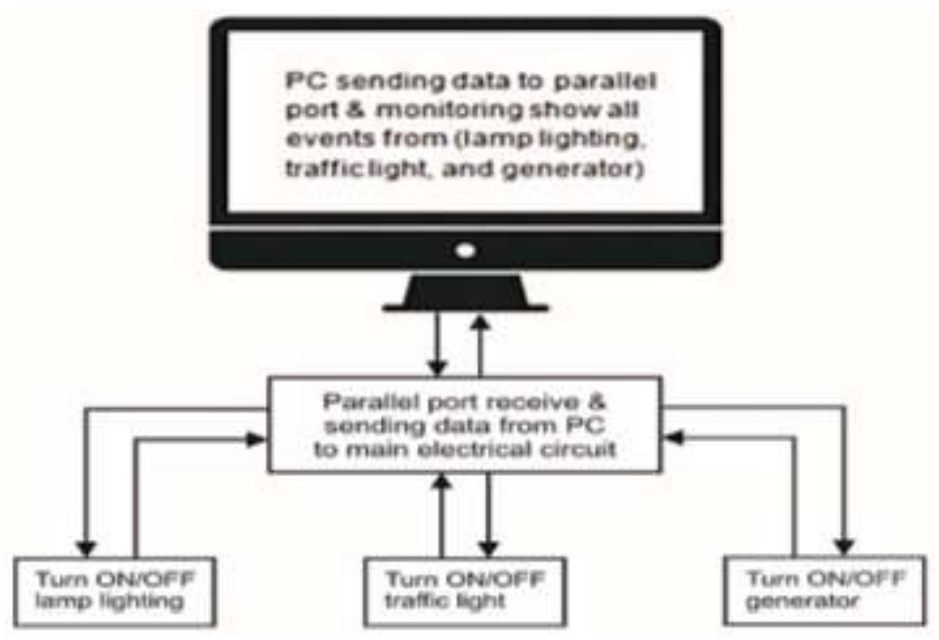

Figure 4. General diagram of the proposed system

\subsection{Parallel port and circuit}

Parallel port (25 pins) as Figure 5 connected between the computer and the circuit to send instructions as a signal and the circuit distributed the signal to turrn on/off the devices. A relay is an electrically activated switch. It depends on internally a coil which will generate a field of a magnetic and attracts a movable lever and then changes switch contacts when a current is flowing through it. The exemplary usage of really switch is to let a low DC voltage in circuit one to turn on or off a high voltage (DC or AC) in circuit two without direct electrical connection between them. This means circuit one and circuit two are magnetically and mechanically linked but not electrically connected. Nine relays $12 \mathrm{~V}$ were used in this proposed system, eight of them were installed directly in the main circuit and Ninth relay was installed in the LDR circuit as shown in Figure 6. 


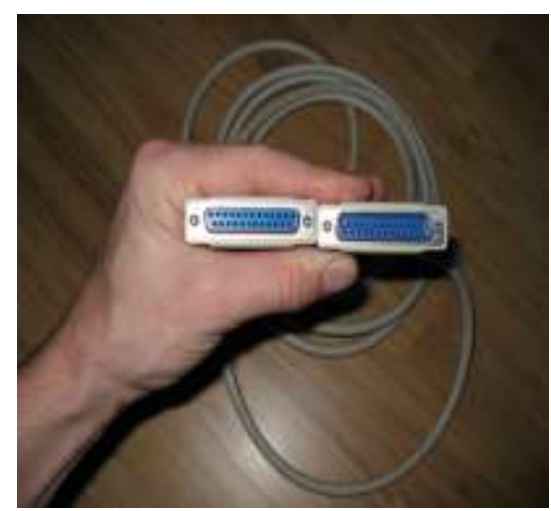

Figure 5. Parallel port with 25 pin out

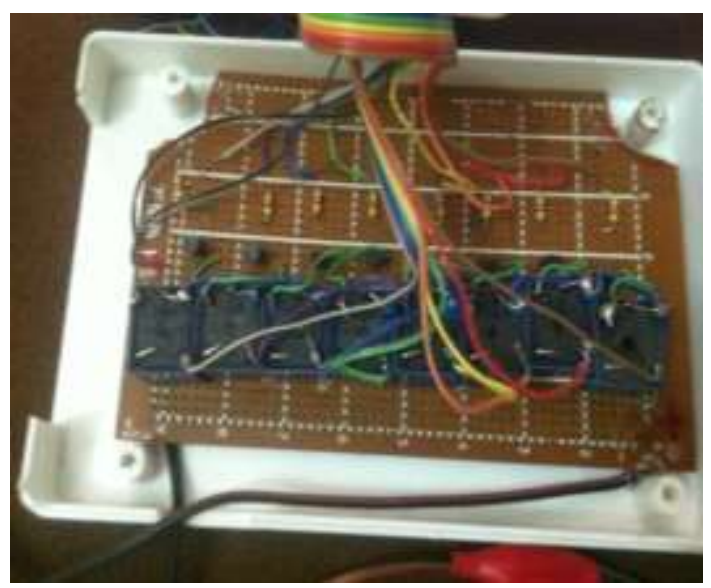

Figure 6. Main circuit of the proposed system

\subsection{Street lighting with light dependent resistor circuit (LDR)}

The light-based resistor (LDR) in this circuit uses a light sensor that LDR resistance will be low if there is light as shown in Figure 7. So the voltage drop across R2. In this case, the transistor BC54 (Q1) will keep ON. The transistor Q1 is connected with transistor BC547 (Q2). So Q2 will be shut down and so do the relay. The lamp will remain OFF. If night falls, the resistance of LDR will be increased to make the voltage difference across the resistor (R2) less than 0.6V. This makes the transistor Q1 turn OFF which in turn makes Q2 ON. The relay will be activated and the lamp will be ON. Adaptation our proposed circuit as shown in Figure 8. We connected with relay in main board in two phases. Figures 7 and 8 illustrate LDR circuit components designed with Proteus V.8 Program.

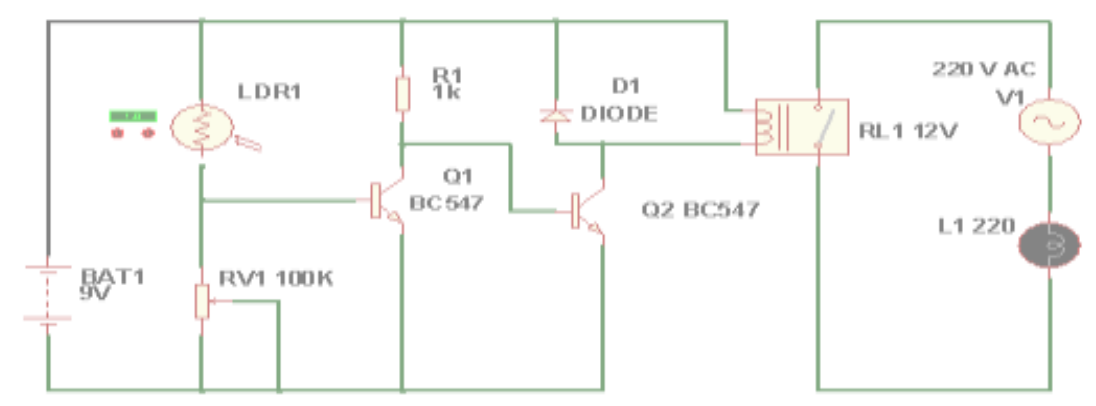

Figure 7. Traditional diagram LDR circuit 


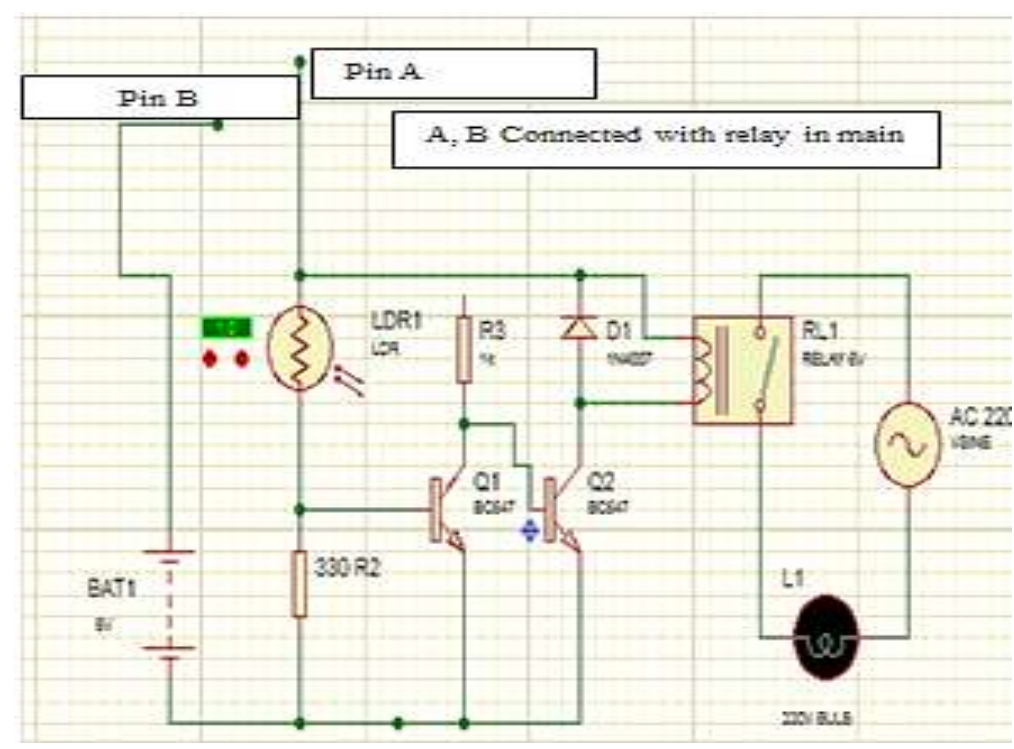

Figure 8. LDR circuit connected with main circuit

\subsection{Traffic light streets}

In this stage using the timer feature which is provided by the V.B program, has been used to control the relay circuit to activate street traffic lights. If the traffic light (T1) is turn ON for $180 \mathrm{sec}$., then the other traffic light (T2, T3, T4) will turn OFF thus, for the rest of other cases in succession. The monitoring system (PC) can be controlled to be turned OFF the traffic light when there is no street congestion and school attendance is over. The flowchart in Figure 9 illustrates all the cases of the traffic light.

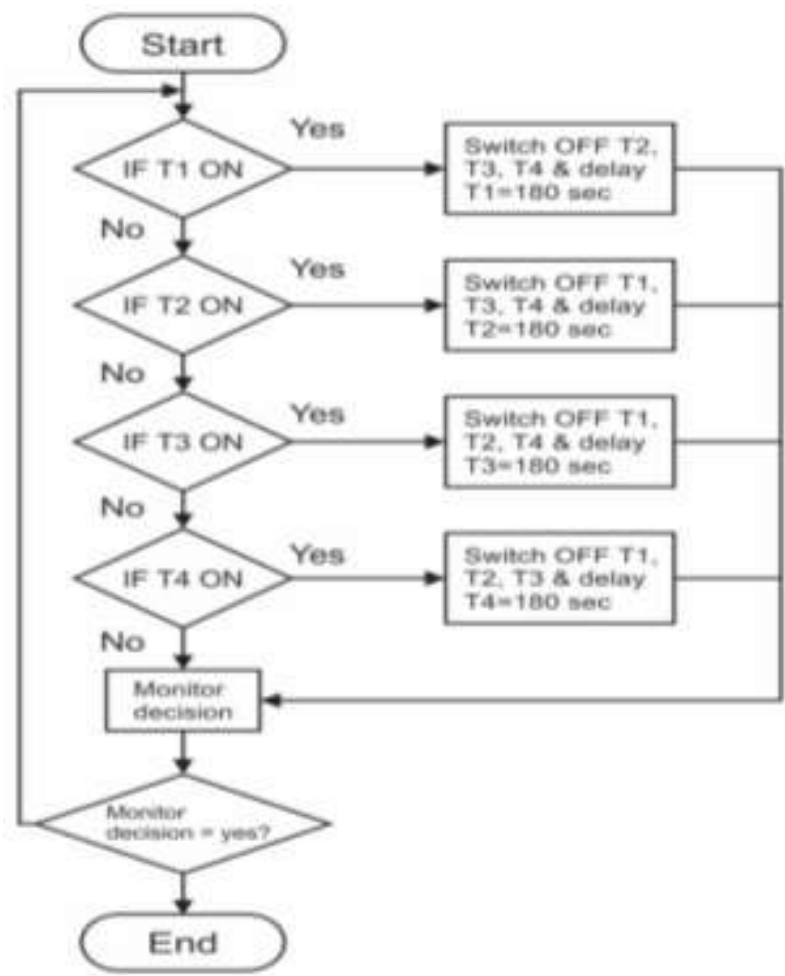

Figure 9. Flowchart shows the work of traffic lights 


\section{RESULTS AND DISCUSSIONS}

In this proposed system, an integrated system was established to operate street lighting, control traffic lights, and operate generators for the virtual city. Two electrical circuits were built. The first is the use of relay systems that control the traffic light operating systems and of the generator. The second section concerns the construction of a dual-functional circuit, which automatically controls the light on the street depending on the external light intensity sensitivity that is using LDR circuit, and also the lighting process is controlled through the computer's system operator by adopting the actual need to turn on the light. Therefore, two mixed systems were combined, which are the open system and the closed system of electrical circuits, and we called it the system Hybrid. All previous systems used the LDR circuit which was not externally controlled which means a significant consumption of electricity, no matter whether the street's illuminates are needed as shown in Figures 10 and 11.

The time length between 03:00 a.m o'clock and the sunrise is longer in the winter so if the dimming is decreased towards to sunrise, energy saving will not be more than before. According to scenario above when lighting control system is operated such as the time length from the sunset to 21:00 a'clock and with $100 \%$ performance, between 09:00 p.m and 11:00 p.m o'clock and 80\% performance, from 03:00 to the sunrise and $70 \%$ performance level, the amount of energy saving is $24.1 \%$ during a year.

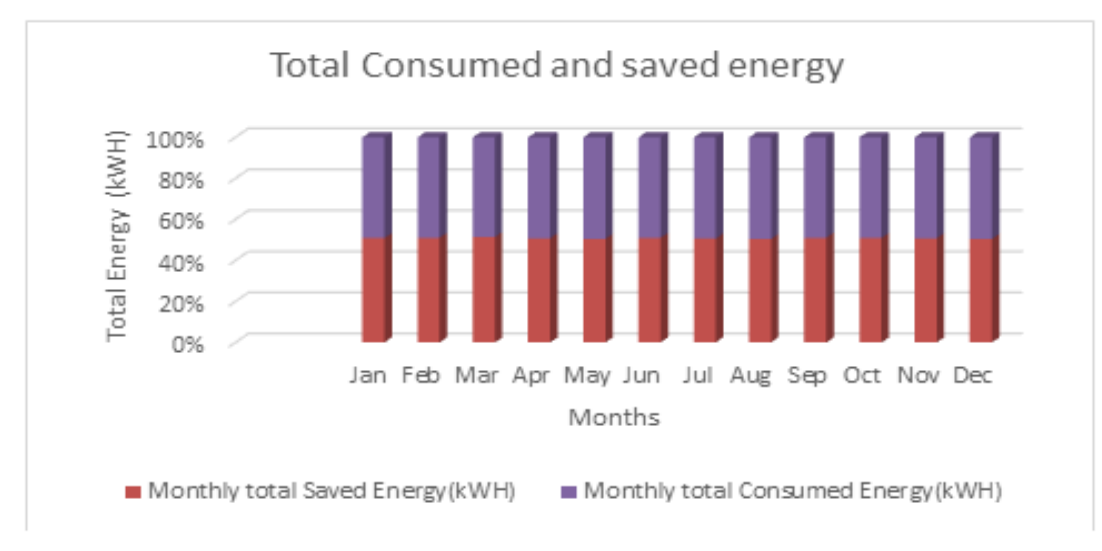

Figure. 10 Total Consumed and saved energy

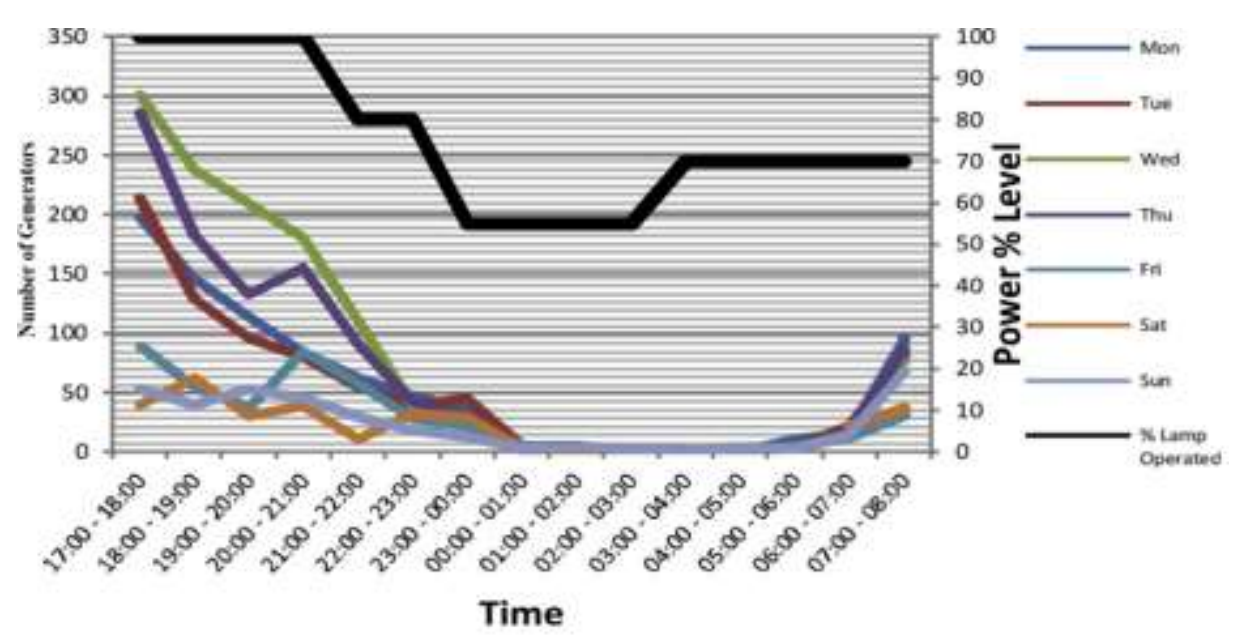

Figure 11. The change of power level and Number of Generators in time

\section{CONCLUSION}

Electronic control systems have many benefits such as reducing financial and administrative spending and contributing to the growth of industrial production. In this system, the open and closed systems were combined together because the two systems have defects in speed, performance and results, thus it 
called a hybrid control system. This system reduces the power consumption by automating the system, reducing the number of supervising workers and facilitating the maintenance and operation of the system for long periods of time and can be controlled by the computer (on demand) by turning off all the circuits associated with it. Electronic circuits for telecommunication networks can be extended to large cities and long distances, through internet systems to speed up transmission and reception signals and speed decision making.

\section{REFERENCES}

[1] R. Zhang, Z. Zhou, W. Wu, C.-C. Lin, P.-H. Tsui, and S. Wu, "An improved fuzzy connectedness method for automatic three-dimensional liver vessel segmentation in CT images," Journal of healthcare engineering, vol. 2018, 2018.

[2] D. Adu Poku, "Analysis and Design of Heat Energy Control System," 2011.

[3] P. Albertos and S. Antonio, Multivariable control systems: an engineering approach: Springer Science \& Business Media, 2006.

[4] A. Alhegazi, Z. Zakaria, N. A. Shairi, T. Sutikno, R. A. Alahnomi, and A. I. Abu-Khadrah, "Analysis and investigation of a novel microwave sensor with high Q-factor for liquid characterization," TELKOMNIKA (Telecommunication, Computing, Electronics and Control), vol. 17, pp. 1065-1070, 2019.

[5] B. Baigzadehnoe, B. Rezaie, and Z. Rahmani, "Fuzzy-model-based fault detection for nonlinear networked control systems with periodic access constraints and Bernoulli packet dropouts," Applied Soft Computing, vol. 80, pp. 465-474, 2019/07/01/ 2019.

[6] R. Banerjee, "Closed loop traffic signal controller," International Journal of Scientific and Research Publications, p. 290, 2015 .

[7] B. Borovic, A. Liu, D. Popa, H. Cai, and F. Lewis, "Open-loop versus closed-loop control of MEMS devices: choices and issues," Journal of Micromechanics and Microengineering, vol. 15, p. 1917, 2005.

[8] N. Bredeche, E. Haasdijk, and A. Prieto, "Embodied evolution in collective robotics: a review," Frontiers in Robotics and AI, vol. 5, p. 12, 2018.

[9] O. A. Hammood, M. N. M. Kahar, W. A. Hammood, R. A. Hasan, M. A. Mohammed, A. A. Yoob, et al., "An effective transmit packet coding with trust-based relay nodes in VANETs," Bulletin of Electrical Engineering and Informatics (BEEI), vol. 9, pp. 685-697, 2020.

[10] O. A. Hammood, M. N. M. Kahar, M. N. Mohammed, W. A. Hammood, and J. Sulaiman, "The VANET-Solution Approach for Data Packet Forwarding Improvement," Advanced Science Letters, vol. 24, pp. 7423-7427, 2018.

[11] O. A. Hammood, N. Nizam, M. Nafaa, and W. A. Hammood, "RESP: Relay Suitability-based Routing Protocol for Video Streaming in Vehicular Ad Hoc Networks," International Journal of Computers, Communications \& Control, vol. 14, 2019.

[12] R. A. Hasan, M. A. Mohammed, Z. H. Salih, M. A. B. Ameedeen, N. Țăpuş, and M. N. Mohammed, "HSO: A Hybrid Swarm Optimization Algorithm for Reducing Energy Consumption in the Cloudlets," TELKOMNIKA (Telecommunication, Computing, Electronics and Control), vol. 16, pp. 2144-2154, 2018.

[13] Z. H. Salih, G. T. Hasan, and M. A. Mohammed, "Investigate and analyze the levels of electromagnetic radiations emitted from underground power cables extended in modern cities," in 2017 9th International Conference on Electronics, Computers and Artificial Intelligence (ECAI), 2017.

[14] Z. H. Salih, G. T. Hasan, M. A. Mohammed, M. A. S. Klib, A. H. Ali, and R. A. Ibrahim, "Study the Effect of Integrating the Solar Energy Source on Stability of Electrical Distribution System," in 2019 22nd International Conference on Control Systems and Computer Science (CSCS), pp. 443-447, 2019.

[15] B. Ching, M. Amoozadeh, C.-N. Chuah, H. M. Zhang, and D. Ghosal, "Enabling performance and security simulation studies of intelligent traffic signal light control with VENTOS-HIL," Vehicular Communications, vol. 24, p. 100230, 2020/08/01/ 2020.

[16] E. El Mandouh and A. G. Wassal, "Automatic generation of hardware design properties from simulation traces," in 2012 IEEE International Symposium on Circuits and Systems, pp. 2317-2320, 2012.

[17] R. A. Gupta and M.-Y. Chow, "Networked control system: Overview and research trends," IEEE transactions on industrial electronics, vol. 57, pp. 2527-2535, 2009.

[18] Z. Hao, R. Boel, and Z. Li, "Model based urban traffic control, part II: Coordinated model predictive controllers," Transportation Research Part C: Emerging Technologies, vol. 97, pp. 23-44, 2018/12/01/ 2018.

[19] E. M. E. Hussein, "Automatic generation of hardware design properties from simulation traces," CU Theses, 2012.

[20] A. Ibrahim, R. R. Alexander, M. S. U. Sanghar, and R. D. D'Souza, "Control Systems in Robotics: A Review," International Journal of Engineering Inventions, vol. 5, pp. 29-38, 2016.

[21] J. Jeong, N. Kim, D. Karbowski, and A. Rousseau, "Implementation of Model Predictive Control into Closed-Loop Micro-Traffic Simulation for Connected Automated Vehicle," IFAC-PapersOnLine, vol. 52, pp. 224-230, 2019/01/01/ 2019.

[22] T. H. Lee, Q. Wang, and K. K. Tan, "Robust Smith-predictor controller for uncertain delay systems," AIChE Journal, vol. 42, pp. 1033-1040, 1996.

[23] A. Lekbir, C. K. Gan, M. R. Ab Ghani, and T. Sutikno, "The Recovery of Energy from a Hybrid System to Improve the Performance of a Photovoltaic Cell," International Journal of Power Electronics and Drive Systems (IJPEDS), vol. 9, p. 957, 2018. 
[24] K. Nielsen, M. B. Nielsen, C. Ogbonnaya, M. Känsälä, E. Saari, and K. Isaksson, "Workplace resources to improve both employee well-being and performance: A systematic review and meta-analysis," Work \& Stress, vol. 31, pp. 101-120, 2017.

[25] Y. Wu, C. Shi, X. Zhang, and W. Yang, "Design of new intelligent street light control system," in IEEE ICCA 2010, pp. 1423-1427, 2010.

[26] B. Yang, M. Liu, H. Kim, and X. Cui, "Luenberger-sliding mode observer based fuzzy double loop integral sliding mode controller for electronic throttle valve," Journal of Process Control, vol. 61, pp. 36-46, 2018/01/01/ 2018.

[27] S. F. Youness and E. C. Lobusov, "Networked Control for Active Suspension System," Procedia Computer Science, vol. 150, pp. 123-130, 2019/01/01/ 2019.

[28] A. H. Ali, "A Survey on Vertical and Horizontal Scaling Platforms for Big Data Analytics," International Journal of Integrated Engineering, vol. 11, pp. 138-150, 2019.

[29] W. Liu, "Computer Control System Application for Electrical Engineering and Electrical Automation," in IOP Conference Series: Materials Science and Engineering, p. 042200, 2018.

[30] A. L. Durga, "Closed Loop Traffic Light Control System Using IR Sensors," International Journal of Scientific and Research Publications, p. 290, 2018.

[31] M. N. H. K. M. Rathore and C. B. H. K. Channi, "Modeling and Simulation of Automatic Street Light Controller using LDR and Micro-Controller." Internasional Journal for Scientific Research and Development, Vol. 5, no. 8, pp. 274-277, 2017.

[32] M. A. Mohammed, I. A. Mohammed, R. A. Hasan, N. Ţăpuş, A. H. Ali, and O. A. Hammood, "Green Energy Sources: Issues and Challenges," in 2019 18th RoEduNet Conference: Networking in Education and Research (RoEduNet), pp. 1-8, 2019.

[33] M. A. Mohammed, R. A. Hasan, M. A. Ahmed, N. Tapus, M. A. Shanan, M. K. Khaleel, et al., "A Focal load balancer based algorithm for task assignment in cloud environment," in 2018 10th International Conference on Electronics, Computers and Artificial Intelligence (ECAI), pp. 1-4, 2018.

[34] M. A. Mohammed, A. A. Kamil, R. A. Hasan, and N. Tapus, "An Effective Context Sensitive Offloading System for Mobile Cloud Environments using Support Value-based Classification," Scalable Computing: Practice and Experience, vol. 20, pp. 687-698, 2019.

[35] N. Q. Mohammed, M. S. Ahmed, M. A. Mohammed, O. A. Hammood, H. A. N. Alshara, and A. A. Kamil, "Comparative Analysis between Solar and Wind Turbine Energy Sources in IoT Based on Economical and Efficiency Considerations," in 2019 22nd International Conference on Control Systems and Computer Science (CSCS), pp. 448-452, 2019. 